\title{
SPACES OF $p$-INTEGRABLE FUNCTIONS WITH RESPECT TO A VECTOR MEASURE DEFINED ON A $\delta$-RING
}

\author{
J. M. Calabuig, M. A. Juan and E. A. SÁnchez Pérez
}

\begin{abstract}
In this paper we study the lattice properties of the Banach lattices $L^{p}(v)$ and $L_{w}^{p}(v)$ of $p$-integrable real-valued functions and weakly $p$-integrable real-valued functions with respect to a vector measure $v$ defined on a $\delta$-ring. The relation between these two spaces, the study of the continuity and some kind of compactness properties of certain multiplication operators between different spaces $L^{p}$ and/or $L_{w}^{q}$ and the representation theorems of general Banach lattices via these spaces play a fundamental role.
\end{abstract}

Mathematics subject classification (2010): Primary 46G10, Secondary 46E30, 46B42. Keywords and phrases: Banach lattice, $\delta$-ring, Vector measure, Integration.

\section{REFERENCES}

[1] C. D. Aliprantis and O. Burkinshaw, Positive Operators, Academic Press, New York, 1985.

[2] J. M. Calabuig, O. Delgado And E. A. SÁnchez PÉrez, Factorizing operators on Banach function spaces through spaces of multiplication operators, J. Math. Anal. Appl. 364, 88-103 (2010).

[3] J. M. Calabuig, O. Delgado, M. A. Juan and E. A. Sánchez Pérez, Banach lattice properties of $L_{w}^{1}$ of a vector measure on a $\delta$-ring, preprint (2010).

[4] G. P. CURBERA, El espacio de funciones integrables respecto de una medida vectorial, $\mathrm{Ph}$. D. Thesis, Univ. of Sevilla, 1992.

[5] G. P. CuRBerA, Operators into $L^{1}$ of a vector measure and applications to Banach lattices, Math. Ann. 293, 317-330 (1992).

[6] G. P. CURBERA AND W. J. RICKER, Banach lattices with the Fatou property and optimal domains of kernel operators, Indag. Math. (N.S.) 17, 187-204 (2006).

[7] G. P. Curbera And W. J. RickeR, The Fatou property in p-convex Banach lattices, J. Math. Anal. Appl. 328, 287-294 (2007).

[8] R. del Campo, A. Fernández, I. Ferrando, F. Mayoral and F. Naranjo, Multiplication Operator on spaces of integrable functions with respect to a vector measure, J. Math. Anal. Appl. 343, 514-524 (2008).

[9] R. del Campo, A. Fernández, I. Ferrando, F. Mayoral and F. Naranjo, Compactness of multiplication operators on spaces of integrable functions with respect to a vector measure in Vector measures, integration and related topics, Operator Theory. Advances and Applications, 201, 109-113 (2009).

[10] O. Delgado, $L^{1}$-spaces of vector measures defined on $\delta$-rings, Arch. Math. 84, 432-443 (2005).

[11] O. Delgado AND M. A. JUAN, Representation of Banach lattices as $L_{w}^{1}$ spaces of a vector measure defined on a $\delta$-ring, Bull. Belg. Math. Soc. Simon Stevin 19, 2 (2012), 239-256.

[12] A. Fernández, F. Mayoral, F. Naranjo, C. Sáez and E. A. Sánchez-Pérez, Spaces of $p$-integrable functions with respect to a vector measure, Positivity 10, 1-16 (2006).

[13] I. FerRando AND F. Galaz-Fontes, Multiplication operators on vector measure Orlicz spaces, Indag. Math. (N.S.) 20(1), 57-71 (2009).

[14] D. R. LEWIS, On integrability and summability in vector spaces, Illinois J. Math. 16, 294-307 (1972).

[15] J. Lindenstrauss And L. TZafriri, Classical Banach Spaces II, Springer, Berlin, 1979.

[16] W. A. J. Luxemburg And A. C. ZaAnen, Riesz Spaces I, North-Holland, Amsterdam, 1971. 
[17] P. R. MASANI AND H. NIEMI, The integration theory of Banach space valued measures and the Tonelli-Fubini theorems. I. Scalar-valued measures on $\delta$-rings, Adv. Math. 73, 204-241 (1989).

[18] P. R. MASANI AND H. NIEMI, The integration theory of Banach space valued measures and the Tonelli-Fubini theorems. II. Pettis integration, Adv. Math. 75, 121-167 (1989).

[19] P. Meyer-Nieberg, Banach Lattices, Springer-Verlag, Berlin-New York, 1991.

[20] S. OKADA, W. J. Ricker AND E. A. SÁNCHEZ PÉREZ, Optimal domain and integral extension of operators acting in function spaces, Operator Theory: Advances and Applications, 180, Birkhäuser Verlag, Basel, 2008.

[21] E. A. SÁNCHEZ PÉREZ, Compactness arguments for spaces of p-integrable functions with respect to a vector measure and factorization of operators through Lebesgue-Bochner spaces, Illinois J. Math. 45 3, 907-923 (2001).

[22] E. PAP, Handbook of Measure Theory, 1, North-Holland, Amsterdam, 2002.

[23] G. F. STEFAnSSON, $L_{1}$ of a vector measure, Le Matematische (Catania) 48, 219-234 (1193).

[24] A. C. ZaAnen, Riesz, Spaces II, North-Holland, Amsterdam, 1983. 